\title{
Oxocyclostylidol, an Intramolecular Cyclized Oroidin Derivative from the Marine Sponge Stylissa caribica ${ }^{\S}$
}

\author{
Achim Grube and Matthias Köck* \\ Alfred-Wegener-Institut für Polar- und Meeresforschung in der Helmholtz-Gemeinschaft, Am Handelshafen 12, D-27570 Bremerhaven, \\ Germany
}

Received October 17, 2005

Pyrrole-imidazole alkaloids are widely distributed in marine sponges of the orders Halichondrida and Agelasida. Chemical investigation of the Caribbean sponge Stylissa caribica has led to the isolation of the first brominated pyrrole-imidazole alkaloid containing an oxidized pyrrole moiety. The isolation and structure elucidation of oxocyclostylidol (1) are discussed in detail.

Sponges of the order Halichondrida and Agelasida are wellknown to be a rich source of pyrrole-imidazole alkaloids. ${ }^{1}$ The structural diversity of this alkaloid family is related to oroidin (2), ${ }^{2}$ which can react in different cyclization reactions. ${ }^{3}$ Products of dimerization reactions are the group of ageliferins and sceptrins, ${ }^{4}$ while the group of axinellamines ${ }^{5}$ and massadine ${ }^{6}$ are oxidized dimerization products of oroidin (2). For example, in monomolecular cyclization reactions of oroidin $(2)$, cyclooroidin $(3)^{7}$ or stevensine $^{8}$ is formed. In all of the described products the bromopyrrole moiety is not modified. In this paper we describe the first pyrrole-imidazole alkaloid from natural sources with a twice oxidized pyrrole moiety.

In our investigation of Caribbean organisms the sponge Stylissa caribica was examined. The sponge was extracted with a mixture of $\mathrm{MeOH} / \mathrm{CH}_{2} \mathrm{Cl}_{2}(1: 1)$, and the crude extract was partitioned by liquid/liquid extraction between $n$-hexane, $n$ - $\mathrm{BuOH}$, and $\mathrm{H}_{2} \mathrm{O}$. The resulting $n$-BuOH fraction was purified by Sephadex LH-20 chromatography. In an HPLC-HRMS screening of all fractions obtained from Sephadex LH-20 chromatography a compound with a mass pattern of $m / z=340 / 342$ was detected, which was consistent with a bromine isotope pattern.

The molecular formula of oxocyclostylidol (1) was established by high-accuracy MS spectra. The structure of $\mathbf{1}$ was elucidated by UV, 2D NMR, and MS/MS spectra. Table 1 summarizes the $1 \mathrm{D}$ and 2D NMR data of $\mathbf{1}$. The high-resolution mass of $\mathrm{m} / \mathrm{z}$ 340.0032 indicated the molecular formula $\mathrm{C}_{11} \mathrm{H}_{11} \mathrm{~N}_{5} \mathrm{O}_{3} \mathrm{Br}([\mathrm{M}+$ $\mathrm{H}]^{+}$) for 1. Under MS/MS conditions the loss of $18 \mathrm{amu}$ of the molecular ion suggested the presence of a hydroxyl group in $\mathbf{1}$.

The carbon skeleton of the new compound $\mathbf{1}$ was elucidated using correlations from ${ }^{1} \mathrm{H},{ }^{1} \mathrm{H}-\mathrm{COSY},{ }^{1} \mathrm{H},{ }^{13} \mathrm{C}-\mathrm{HMBC},{ }^{1} \mathrm{H},{ }^{15} \mathrm{~N}-\mathrm{HMBC}$, and 1,1-ADEQUATE experiments. The comparison of the ${ }^{15} \mathrm{~N}$-chemical shifts of $\mathbf{1}$ and $\mathbf{2}$ indicated a change in the pyrrole ring but no changes in the imidazole moiety (see Figure 1). This is also confirmed by the identical number of correlations obtained in the ${ }^{1} \mathrm{H},{ }^{15} \mathrm{~N}-\mathrm{HMBC}$ of $\mathbf{1}$ in comparison to oroidin (2). The ${ }^{13} \mathrm{C} \mathrm{NMR}$ signals at $\delta 110.9,121.9$, and $146.9 \mathrm{ppm}$ are identical for the imidazole moiety in oroidin (2). Compared to $\mathbf{2}$ the signal for C-10 $(\mathbf{1}, 98.5 ; \mathbf{2}, 126.4 \mathrm{ppm})$ is shifted to higher fields in $\mathbf{1}$, whereas the signal for C-9 $(\mathbf{1}, 130.3 ; \mathbf{2}, 112.7 \mathrm{ppm})$ is shifted to lower fields. These values supported a major change in the electron density of the double bond and indicated a directly bound heteroatom to C-9 or $\mathrm{C}-10$. In combination with the correlation from $\mathrm{H}-10$ to $\mathrm{N}-1$ in

$\S$ Presented at the 4th European Conference on Marine Natural Products, Paris, France, Sept 12-16, 2005 (Book of Abstracts, pp OC 09 and P 69).

* To whom correspondence should be addressed. Tel: +49-471-48311497. Fax: +49-471-48311425. E-mail: mkoeck@ awi-bremerhaven.de.
Table 1. NMR Data of Oxocyclostylidol (1) Recorded in DMSO- $d_{6}{ }^{a}$

\begin{tabular}{|c|c|c|c|c|}
\hline no. & $\delta_{\mathrm{C}^{b}}$ & $\delta_{\mathrm{H}}$ & ${ }^{1} \mathrm{H},{ }^{13} \mathrm{C}-\mathrm{HMBC} c$ & ${ }^{1} \mathrm{H},{ }^{15} \mathrm{~N}-\mathrm{HMBC}$ \\
\hline 1 & $(150)$ & & & \\
\hline 2 & 86.6 & & & \\
\hline $2-\mathrm{OH}$ & & $7.95(\mathrm{~s})$ & $2,3,6$ & \\
\hline 3 & 144.5 & $7.75(\mathrm{~s})$ & $\underline{2}, \underline{4}, 5,9$ & 1 \\
\hline 4 & 119.5 & & & \\
\hline 5 & 162.2 & & & \\
\hline 6 & 165.4 & & & \\
\hline 7 & (104) & $8.55(\mathrm{~d}, J=5.3 \mathrm{~Hz})$ & $2,3,6,8,9$ & \\
\hline 8 & 40.6 & $\begin{array}{l}4.30(\mathrm{dd}, J=2.2,17.0 \mathrm{~Hz}) / \\
4.09(\mathrm{dd}, J=5.3,17.0 \mathrm{~Hz})\end{array}$ & $6, \underline{9}, 10,11$ & 1,7 \\
\hline 9 & 130.3 & & & \\
\hline 10 & 98.5 & $7.01(\mathrm{~s}, \mathrm{br})$ & $8, \underline{9}, \underline{11}, 12$ & 1,15 \\
\hline 11 & 121.9 & & & \\
\hline 12 & 110.9 & $6.85(\mathrm{~s}, \mathrm{br})$ & $8,9,10,11,14$ & 13,15 \\
\hline 13 & (137) & $12.31(\mathrm{~s}, \mathrm{br})$ & & \\
\hline 14 & 146.9 & & & \\
\hline 15 & (138) & $12.44(\mathrm{~s}, \mathrm{br})$ & & \\
\hline 16 & (59) & $7.58(\mathrm{~s}, \mathrm{br})$ & & 13,15 \\
\hline
\end{tabular}

${ }^{a}{ }^{1} \mathrm{H}$ and ${ }^{13} \mathrm{C}$ chemical shifts $[\mathrm{ppm}]$ are referenced to the DMSO- $d_{6}$ signal (2.50 and $39.5 \mathrm{ppm}$, respectively). COSY correlations appear between $\mathrm{H}-7 / \mathrm{H}-8\left({ }^{3} J_{\mathrm{HH}}\right)$ and $\mathrm{H}-8 / \mathrm{H}-10\left({ }^{4} J_{\mathrm{HH}}\right) .{ }^{b}$ For positions $1,7,13$, and $15, \delta_{\mathrm{N}}$ is given in the $\delta_{\mathrm{C}}$ column. ${ }^{15} \mathrm{~N}$ NMR spectra were not calibrated with an external standard. The $\delta$ value has an accuracy of about $1 \mathrm{ppm}$ in reference to $\mathrm{NH}_{3}(0 \mathrm{ppm}) .{ }^{c} \mathrm{HMBC}$ correlations that also appear in the 1,1-ADEQUATE spectrum are underlined in the HMBC column. The correlations from $\mathrm{H}-3$ to $\mathrm{C}-9, \mathrm{H}-7$ to $\mathrm{C}-3, \mathrm{H}-8$ to C-11, and $\mathrm{H}-12$ to C-9 represent interactions over four bonds $\left({ }^{4} J_{\mathrm{CH}}\right)$. The correlation from $\mathrm{H}-12$ to $\mathrm{C}-8$ represents an interaction over five bonds $\left({ }^{5} J_{\mathrm{CH}}\right)$.

the ${ }^{1} \mathrm{H},{ }^{15} \mathrm{~N}-\mathrm{HMBC}$ (see Supporting Information, Figure S1) this indicates the presence of an en-amine structure.

In contrast to other pyrrole-imidazole alkaloids the ${ }^{1} \mathrm{H}$-signal of the pyrrole $\mathrm{NH}$ was missing and the ${ }^{15} \mathrm{~N}$-chemical shift for the pyrrole nitrogen was shifted to higher fields (from 166 to $150 \mathrm{ppm}$ ) compared to oroidin (2). Three correlations to N-1 were observed in the ${ }^{1} \mathrm{H},{ }^{15} \mathrm{~N}-\mathrm{HMBC}$ of $\mathbf{1}$ in constrast to oroidin (2), with only one correlation (see Supporting Information, Figure S1). The four remaining carbon atoms of the pyrrole moiety in $\mathbf{1}$ showed completely different chemical shifts $(86.6,119.5,144.5,162.2 \mathrm{ppm})$ from those obtained for monobrominated pyrrole alkaloids. The most downfield carbon atom at $162.2 \mathrm{ppm}$ suggested the presence of an amide or ester function, whereas a ${ }^{13} \mathrm{C}$ shift of $86.6 \mathrm{ppm}$ is typical for a semi-aminale structure as observed in massadine (4). ${ }^{6}$ The remaining two carbon atoms at 119.5 and $144.5 \mathrm{ppm}$ form the double bond in which the bromine atom is attached to the carbon atom at $119.5 \mathrm{ppm}$. The low-field shifted ${ }^{1} \mathrm{H}$ NMR signal of $\delta 144.5$ and the ${ }^{1} \mathrm{H},{ }^{15} \mathrm{~N}-\mathrm{HMBC}$ correlation between $\mathrm{H}-3$ and $\mathrm{N}-1$ (see Supporting Information, Figure S1) supported the existence of an $\alpha, \beta$-unsaturated lactame. The structure of the pyrrole moiety was 


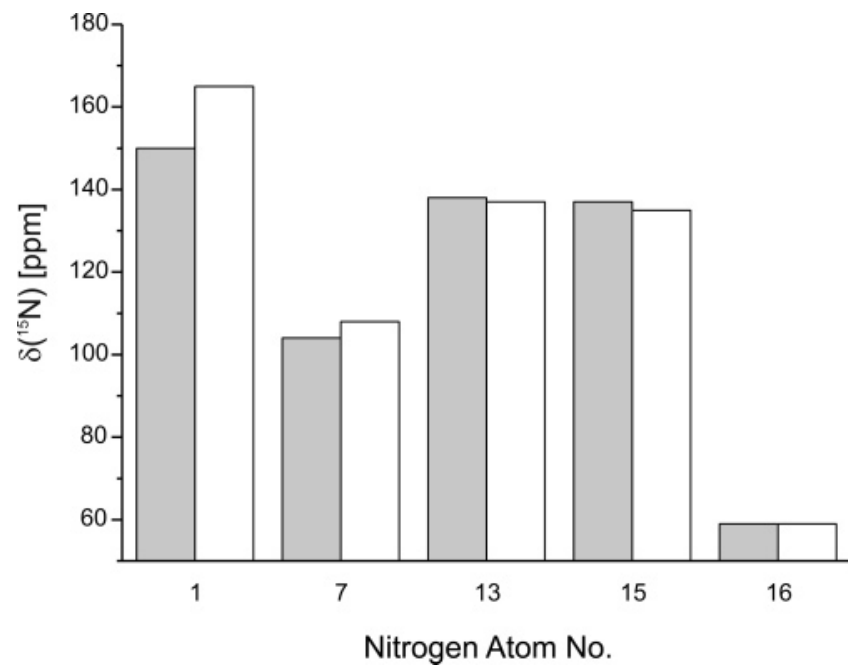

Figure 1. Graphical comparison of $\delta\left({ }^{15} \mathrm{~N}\right)$ of $\mathbf{1}$ (gray bars) and 2 (white bars).

finally established by ${ }^{1} \mathrm{H},{ }^{13} \mathrm{C}-\mathrm{HMBC}$ correlations between $\mathrm{H}-3$ and C-2, C-4, and C-5 (see Supporting Information, Figure S2) and 1,1-ADEQUATE correlations from $\mathrm{H}-3$ to $\mathrm{C}-2$ and $\mathrm{C}-4$ (see Supporting Information, Figure S3). The connection of the semiaminale with the amide moiety is supported by a sharp ${ }^{1} \mathrm{H}$ NMR signal of the hydroxyl group indicating a hydrogen bond with the amide carbonyl. All these facts suggested a twice oxidized pyrrole system for oxocyclostylidol (1). This $\alpha$-bromo, $\gamma$-hydroxy, $\alpha, \beta$ unsaturated $\gamma$-butyrlactame system has not previously been observed in brominated pyrrole-imidazole alkaloids from natural sources. The configuration of the double bond between C-9/C-10 was assigned by ROESY spectra with different mixing times (150 and $200 \mathrm{~ms}$ ). A strong ROE between $\mathrm{H}-8 / \mathrm{H}-12$ and a missing ROE between $\mathrm{H}-10 / \mathrm{H}-12$ indicated an $E$ configuration of the double bond.

While semi-aminale structures are in general unstable, this structural element is known to be stable in neutral media (no hydrolysis products were detected in HPLC) in pyrrole-imidazole alkaloids. Massadine (4) and the axinellamines ${ }^{5}$ are stable compounds containing a semi-aminale structure. The structure of $\mathbf{1}$ included a vinylogous system between $\mathrm{N}-1$ and the guanidine group, which is in accordance with the long-wave absorption maximum in the UV spectrum $(320 \mathrm{~nm})$. The absorption maximum at 263 $\mathrm{nm}$ is in the same region as for known pyrrole-imidazole alkaloids.

To verify the proposed structure of $\mathbf{1}$, CoCON calculations ${ }^{9}$ were carried out. For the experimental data set CoCON generated four

Chart 1. Structural Formulas of Oxocyclostylidol (1), Oroidin (2), Cyclooroidin (3), and Massadine (4)<smiles>Nc1ncc(C=C2CNC(=O)[C@]3(O)C=C(Br)C(=O)N23)[nH]1</smiles>

1

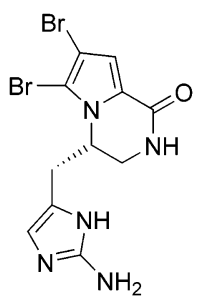

3<smiles>Nc1ncc(/C=C/CNC(=O)c2cc(Br)c(Br)[nH]2)[nH]1</smiles>

2

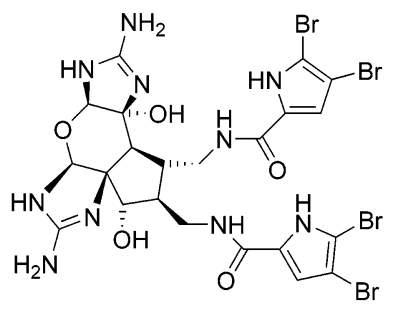

4
Chart 2. Four Structural Proposals for Oxocyclostylidol (1) Generated by $\mathrm{COCON}^{a}$<smiles>Nc1ncc(/C=C2/CNC(=O)C3(O)C=C2C(=O)C3Br)[nH]1</smiles><smiles>Nc1ncc(/C=C2\CNC(=O)C3(O)C=C(Br)N23)[nH]1</smiles><smiles>Nc1ncc(/C=C2\CNC(=O)C3(O)C=C(Br)C(=O)N23)[nH]1</smiles><smiles>Nc1ncc(/C=C2/CNC(=O)C3(O)C=C(Br)N(C2)C3=O)[nH]1</smiles>

${ }^{a}$ All experimental data including correlations from ${ }^{1} \mathrm{H},{ }^{15} \mathrm{~N}-\mathrm{HMBC}$ and $1,1-$ ADEQUATE were used as input for this COCON calculation.
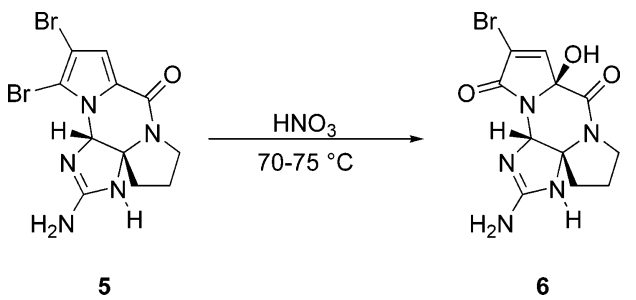

Figure 2. Reaction of dibromophakellin (5) with dilute nitric acid to the oxidized product $6 .{ }^{11}$

structural proposals (see Chart 2), which included the structure of oxocyclostylidol (1). The other three proposals can be neglected because two of them represent strained structures and the last is a carboxylic acid bromide. When running the COCON calculations without the 1,1-ADEQUATE data and the ${ }^{1} \mathrm{H},{ }^{15} \mathrm{~N}-\mathrm{HMBC}$ data, the number of possible structures increases rapidly. ${ }^{9}$ The calculation without the ${ }^{1} \mathrm{H},{ }^{15} \mathrm{~N}-\mathrm{HMBC}$ data led to more than 50000 structural proposals. This number increases to more than 150000 structural proposals if the 1,1-ADEQUATE data were also not used. These numbers demonstrated the importance of the ${ }^{1} \mathrm{H},{ }^{15} \mathrm{~N}-\mathrm{HMBC}$ data for the unambiguous structure elucidation of oxocyclostylidol (1) ${ }^{10}$

To the best of our knowledge, oxocyclostylidol (1) is the first pyrrole-imidazole alkaloid from natural sources that includes an oxidized pyrrole moiety. The carbon-nitrogen skeleton of $\mathbf{1}$ is identical to cyclooroidin (3). ${ }^{7}$ Biosynthetically, oxocyclostylidol (1) could be derived from an intramolecular cyclized oroidin (2) that is twice oxidized under loss of bromine in position 5. This is supported by synthetic approaches to oxidized bromopyrrole moieties. This functionality is known from the reaction of dibromophakellin (5) with dilute nitric acid ${ }^{11}$ and as a byproduct in the biomimetic synthesis of dibromophakellin (5) ${ }^{12}$ (see Figure 2).

The new structure of oxocyclostylidol (1) includes some interesting functional groups that could induce biological or pharmacological effects, which are still under investigation. Oxocyclostylidol (1) was tested against several pathogenic bacteria, fungi, and cultures of mice fibroblasts, but showed only minor activity in these tests. Determination of the absolute configuration will be carried out by synthesis.

\section{Experimental Section}

General Experimental Procedures. Optical rotation was measured with a Perkin-Elmer $241 \mathrm{MC}$ polarimeter at $23{ }^{\circ} \mathrm{C}$. CD spectra were recorded with a Jasco J-810 system. UV spectra were recorded with a DAD (Agilent) during HPLC analysis. ${ }^{1} \mathrm{H}$ NMR and ${ }^{13} \mathrm{C}$ NMR spectra were recorded on Bruker Avance 400 and 600 NMR spectrometers. All experiments were measured at 298 or $300 \mathrm{~K}$ (sample concentration: $9.5 \mathrm{mg} / 600 \mu \mathrm{L}$ ). The DQF- ${ }^{1} \mathrm{H},{ }^{1} \mathrm{H}-\mathrm{COSY},{ }^{1} \mathrm{H},{ }^{13} \mathrm{C}-\mathrm{HSQC},{ }^{1} \mathrm{H},{ }^{13} \mathrm{C}-$ HMBC, ${ }^{1} \mathrm{H},{ }^{15} \mathrm{~N}-\mathrm{HSQC},{ }^{1} \mathrm{H},{ }^{15} \mathrm{~N}$-HMBC, 1,1-ADEQUATE, and ${ }^{1} \mathrm{H},{ }^{1} \mathrm{H}-$ ROESY experiments were carried out using standard parameters. 
HPLC-MS analyses were performed with an Agilent 1100 HPLC system and a Bruker Daltonics microTOF $F_{\mathrm{LC}}$ mass spectrometer. Separation was achieved by a Waters XTerra $\mathrm{RP}_{18}$ column $(3.0 \times 150 \mathrm{~mm}, 3.5 \mu \mathrm{m})$ applying a $\mathrm{MeCN} / 0.01 \% \mathrm{HCOOH}$ (in water) gradient (0 min: $10 \%$ $\mathrm{MeCN} / 90 \% \mathrm{HCOOH}(0.01 \%) ; 30 \mathrm{~min}: 60 \% \mathrm{MeCN} / 40 \% \mathrm{HCOOH}$ $(0.01 \%)$ ) with a flow rate of $0.4 \mathrm{~mL} / \mathrm{min}$. ESIMS/MS spectra were recorded with an Esquire 3000+ ion trap (Bruker Daltonics).

Animal Material. The sponge Stylissa caribica was collected by scuba at Little San Salvador in the Bahamas (74 ft depth, July 2000). The samples were immediately frozen after collection and kept at -20 ${ }^{\circ} \mathrm{C}$ until extraction. The sponge material was identified as previously described. ${ }^{13}$

Extraction and Isolation. The freeze-dried sponge samples of $S$. caribica $(94.7 \mathrm{~g}$ ) were crushed with a mill and extracted at RT exhaustively in a 1:1 mixture of $\mathrm{CH}_{2} \mathrm{Cl}_{2} / \mathrm{MeOH}$. The orange-colored crude extract of $S$. caribica was partitioned between $n$-hexane $(4 \times$ $400 \mathrm{~mL})$ and $\mathrm{MeOH}(300 \mathrm{~mL})$. The $\mathrm{MeOH}$ extract was then partitioned between $n-\mathrm{BuOH}(3 \times 500 \mathrm{~mL})$ and $\mathrm{H}_{2} \mathrm{O}(300 \mathrm{~mL})$. The resulting $n$ - $\mathrm{BuOH}(15.9 \mathrm{mg})$ phase from the solvent-partitioning scheme was purified by gel chromatography on Sephadex LH-20 (Pharmacia) using $\mathrm{MeOH}$ as mobile phase. Final purification of the isolated compound was achieved by preparative $\mathrm{RP}_{18} \mathrm{HPLC}$ on a Kromasil $\mathrm{RP}_{18}$ column $(16 \times 250 \mathrm{~mm}, 10 \mu \mathrm{m})$ applying a MeCN/TFA $(0.1 \%$ in water $)$ gradient to afford 1 ( $29.5 \mathrm{mg}, 0.03 \%$ of dry weight).

Oxocylostylidol (1): yellow powder; $[\alpha]_{\mathrm{D}}^{23}-12$ ( $c$ 1, MeOH); UV (DAD) $\lambda_{\max } 224,263$, and $320 \mathrm{~nm} ; \mathrm{CD}(\mathrm{MeCN}) \lambda(\Delta \epsilon) 208(-6.1)$, $235(1.7), 270(1.5), 304(-0.4) \mathrm{nm} ; \mathrm{HPLC} / \mathrm{HR}(+)$ ESIMS $t_{\mathrm{R}}=3.1$ $\min , m / z, 340.0032[\mathrm{M}+\mathrm{H}]^{+}$(calcd for $\mathrm{C}_{11} \mathrm{H}_{11} \mathrm{~N}_{5} \mathrm{O}_{3}{ }^{79} \mathrm{Br} 340.0040$ ), $\Delta m=1.8)$

Acknowledgment. The sponge collection was carried out by $\mathrm{M}$. Assmann during a scientific expedition to the Bahamas in 2000. During this time the project was sponsored by the DFG (Ko1314/3-1 to 3-4). We acknowledge the support of J. R. Pawlik (University of North Carolina at Wilmington), who gave members of the Köck research group the opportunity to participate in the scientific sojourns to the Bahamas in the years 1998, 1999, 2000, 2001, and 2003. We further thank E. Lichte for performing preparative HPLC analysis, F. Sasse (GBF, Braunschweig) for biological testing, and T. Lindel (LMU München) for measuring the $\mathrm{CD}$ spectra.

Supporting Information Available: NMR spectra $\left({ }^{1} \mathrm{H},{ }^{13} \mathrm{C}-\mathrm{HMBC}\right.$, ${ }^{1} \mathrm{H},{ }^{15} \mathrm{~N}-\mathrm{HMBC}$, and 1,1-ADEQUATE) and CD spectrum in acetonitrile of oxocyclostylidol (1). This material is available free of charge via the Internet at http://pubs.acs.org.

\section{References and Notes}

(1) Faulkner, D. J. Nat. Prod. Rep. 2002, 19, 1-48.

(2) (a) Forenza, S.; Minale, L.; Riccio, R.; Fattorusso, E. J. Chem. Soc D 1971, 1129-1130. (b) Garcia, E. E.; Benjamin, L. E.; Fryer, R. I. J. Chem. Soc., Chem. Commun. 1973, 78-79. (c) Walker, R. P.; Faulkner, D. J.; van Engen, D.; Clardy, J. J. Am. Chem. Soc. 1981, 103, 6772-6773.

(3) Al Mourabit, A.; Potier, P. Eur. J. Org. Chem. 2001, 237-243.

(4) Keifer, P. A.; Schwartz, R. E.; Koker, M. E. S.; Hughes, R. G., Jr.; Rittschof, D.; Rinehart, K. L. J. Org. Chem. 1991, 56, 2965-2975; errata 5736, 6728.

(5) Urban, S.; De Almeida Leone, P.; Carroll, A. R.; Fechner, G. A.; Smith, J.; Quinn, R. J.; Hooper, J. N. A. J. Org. Chem. 1999, 64, $731-735$.

(6) Nishimura, S.; Matsunaga, S.; Fusetani, N.; Shibazaki, M.; Suzuki, K.; Furihata, K.; van Soest, R. W. M. Org. Lett. 2003, 5, 22552257.

(7) Fattorusso, E.; Taglialatela-Scafati, O. Tetrahedron Lett. 2000, 41, 9917-9922.

(8) Albizati, K. F.; Faulkner, D. J. J. Org. Chem. 1985, 50, 4163-4164

(9) (a) Lindel, T.; Junker, J.; Köck, M. J. Mol. Model. 1997, 3, 364368. (b) Lindel, T.; Junker, J.; Köck, M. Eur. J. Org. Chem. 1999 573-577. (c) Köck, M.; Junker, J.; Maier, W.; Will, M.; Lindel, T. Eur. J. Org. Chem. 1999, 579-586.

(10) Köck, M.; Junker, J.; Lindel, T. Org. Lett. 1999, 1, 2041-2044.

(11) Sharma, G.; Magdoff Fairchild, B. J. Org. Chem. 1977, 42, 41184124.

(12) Foley, L. H.; Büchi, G. J. Am. Chem. Soc. 1982, 104, 1776-1777.

(13) Grube, A.; Lichte, E.; Köck, M. J. Nat. Prod. 2006, 69, 125-127.

NP050408F 